\title{
COMPLEX ADMIXTURES FOR HIGH-STRENGTH CONCRETE
}

\author{
Gintautas Skripkiūnas', Žymantas Rudžionis² ${ }^{2}$ Vitoldas Vaitkevičius ${ }^{3}$ \\ Dept of Building Materials, Kaunas University of Technology, \\ Studentu g. 48, LT-3031, Kaunas, Lithuania. \\ ${ }^{1}$ Gintautas.Skripkiunas@saf.ktu.lt2 Zymantas.Rudzionis@saf.kiu.lt \\ 3 Vitoldas.Vaitkevicius@saf.ktu.lt
}

Received 04 Apr 2001; accepted 10 June 2002

\begin{abstract}
The influence of naphthalene formaldehyde superplasticizers (NFS), lignosulfonate plasticizers (LSP) and silica fume on cement paste properties and complex usage of these admixtures for high-strength concrete production are investigated in this research.

These admixtures influence the cement hydration products morphology and properties of hardened cement paste. The degree of cement hydration and $\mathrm{Ca}(\mathrm{OH})_{2}$ content in hardened cement paste were determined for analysis of cement hydration process with admixtures. Mechanical properties and porosity of hardened cement paste with the admixtures were tested. Optimal dosages of plasticizing admixtures and silica fume were estimated and the most efficient method of silica fume adding to concrete mixture was proposed. The results of investigation have been used for high-strength concrete production.
\end{abstract}

Keywords: concrete, portlandcement, admixture, superplasticizer, silica fume, normal consistency of cement paste, degree of hydration, compressive strength, mixing technology.

\section{Introduction}

The main principle of high-strength concrete production is a considerable decrease of $\mathrm{V} / \mathrm{C}$ ratio in concrete. To produce a high-strength and long-durability concrete, it is important to use effective plasticizing admixtures to decrease water requirement in the concrete and to entrain a sufficient amount of air in case of production of frost resistant concrete.

Plasticizers decrease the demand of water in concrete mixture up to $15 \%$. The most popular ones are being produced on the base of lignosulfonate. Lignosulfonate plasticizers (LSP), alongside with plasticizing effect, are known for their air entraining effect [1]. Superplasticizers decrease the demand of water in concrete mixture up to $40 \%$. The most popular admixtures of this kind in Lithuania are naphthalene formaldehyde superplasticizers (NFS), that are based on naphthalene sulphates and formaldehyde [1-7]. Superplasticizers do not only considerably decrease the amount of water in concrete mixtures but also influence the process of cement hydration and the properties of hardened cement paste $[2,8,9]$.

Silica fume, a very active mineral admixture, is used in production of high-strength concrete. Due to a very active pozzolanic effect silica fume increases concrete strength, although due to their great specific surface area, it also considerably increases the water demand in con- crete mixture [10-14]. Therefore using silica fume it is important to increase considerably the amount of plasticizing admixture in the concrete.

The research aim is to determine the influence of complex admixtures, being composed from naphthalene formaldehyde or melamine formaldehyde superplasticizers and lignosulfonates as well as silica fume, on cement mixtures and concretes properties, to investigate properties of such type of concretes and possibilities to use the above-mentioned admixtures in high-strength concrete production.

\section{The influence of complex admixtures on cement paste properties}

Naphthalene formaldehyde superplasticizer S-3, lignosulfonates, silica fume, as a powder, from Ukraine metallurgic plants and portlandcement CEM I 42,5 R, produced by $A B$ "Akmenès cementas" have been used in the experimental research.

Cement pastes were mixed manualy for approximately 5 min. Plasticizing admixtures were added together with water used to mix the concrete. At the beginning of experiments silica fume was mixed with cement, then the obtained dry binder was mixed with water. Water requirements for normal consistency cement paste as well as setting time were determined by Vikat 
apparatus. For hardened cement paste properties testing samples-prisms $4 \times 4 \times 16 \mathrm{~cm}$ were formed. They were compacted by vibration on a vibrating table and cured for 28 days in a regime chamber at $20 \pm 2 \mathrm{C}^{\circ}$ and $95 \pm 5 \%$ relative humidity. Compressive and bending strength of hardened cement paste was determined by testing the samples. Porosity parametres of hardened cement paste were determined according to water absorption kinetics (GOST 12730.4-78). For this reason splitted samples of about $4 \times 4 \times 4 \mathrm{~cm}$ were used.

The research results indicate that with the increase of the quantity of naphthalene formaldehyde superplasticizer the water requirement for normal consistency cement paste does not decrease proportionally (Fig 1). This admixture is effective adding it to the cement paste up to $1,5 \ldots 2 \%$ (dry material) of cement mass. Increasing the plasticizers amount above the mentioned values fractionally reduces water requirement for normal consistency cement paste.

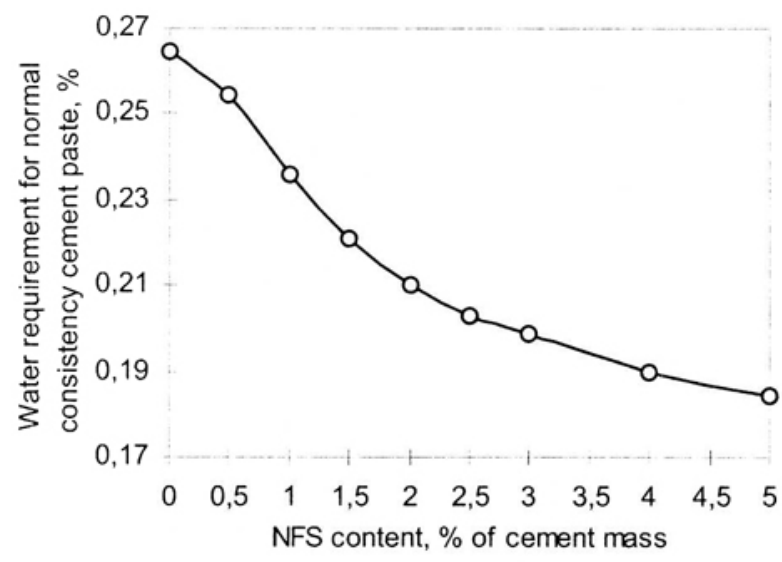

Fig 1. Relationship between water requirement for normal consistency cement paste and naphthalene formaldehyde superplasticizer (NFS) content

Analysing naphthalene formaldehyde superplasticizer effect on the cement hydration process and on the properties of hardened cement paste, it was defined a great effect of this admixture on cement hydration products morphology in hardened cement paste and properties of this paste. The plasticizing effect of this admixture on cement paste is quite well due to water solution surface tension reduction and increasing of cement particles surface watering and electrokinetic $\zeta$ - potential. But admixture adsorption on the cement particles surface reduces the degree of crystallization of cement hydration products resulting in the hardened cement paste compressive strength reduction and cement hydration process slowdown $[8,9]$. This has been proved by the results of cement hydration degree and $\mathrm{Ca}(\mathrm{OH})_{2}$ quantity investigation (Table 1).

Compressive strength of hardened cement paste is under the influence of $\mathrm{V} / \mathrm{C}$ ratio but the above-mentioned effect of admixtures on cement hydration process and cement hydration products morphology have an influence too.
Table 1. The influence of naphthalene formaldehyde superplasticizer (NFS), lignosulfonates (LSP) and silica fume $\left(\mathrm{SiO}_{2}\right)$ on the degree of cement hydration and hydration products

\begin{tabular}{|c|c|c|}
\hline $\begin{array}{c}\text { Admixtures } \\
\text { content, \% of } \\
\text { cement mass }\end{array}$ & $\begin{array}{c}\text { Degree of cement } \\
\text { hydration, } \%\end{array}$ & $\begin{array}{c}\mathrm{Ca}(\mathrm{OH})_{2} \text { content. } \\
\%\end{array}$ \\
\hline- & 75,7 & 14,3 \\
\hline $1 \% \mathrm{NFS}$ & 78,2 & 14,3 \\
\hline $3 \% \mathrm{NFS}$ & 73.3 & 4,7 \\
\hline $5 \% \mathrm{NFS}$ & 65,6 & 3,3 \\
\hline $1 \% \mathrm{NFS}+0,3 \% \mathrm{LSP}$ & 72.9 & 12,5 \\
\hline $5 \% \mathrm{SiO}_{2}$ & 80,6 & 10,7 \\
\hline $15 \% \mathrm{SiO}_{2}$ & 89.1 & 7,9 \\
\hline $1 \% \mathrm{NFS}+5 \% \mathrm{SiO}_{2}$ & 79.7 & 8.6 \\
\hline $1 \% \mathrm{NFS}+15 \% \mathrm{SiO}_{2}$ & 79,7 & 5.3 \\
\hline
\end{tabular}

Due to the complex infuence of these two factors the compressive and bending strength of hardened cement paste increases only with increasing of naphthalene formaldehyde superplasticizer quantity up to a certain level ( Fig 2).

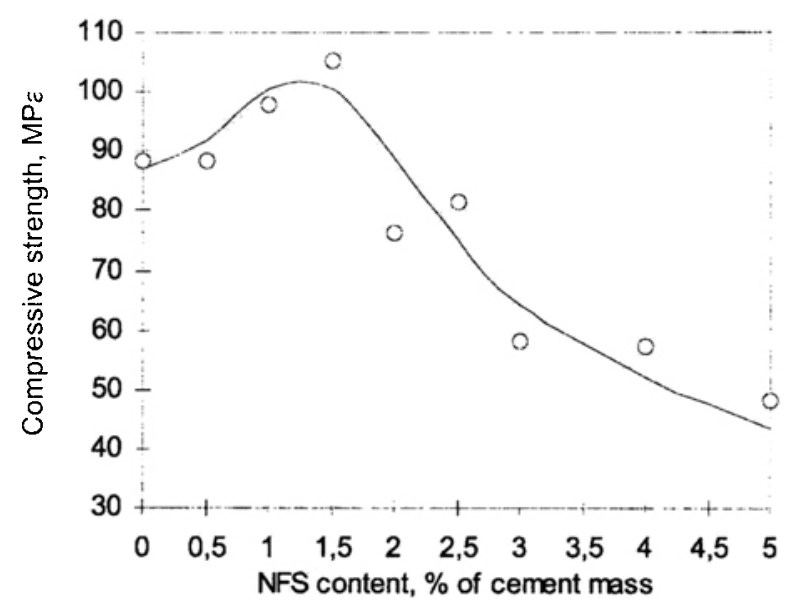

Fig 2. Relationship between hardened cement paste compressive strength and naphthalene formaldehyde superplasticizer (NFS) content

The optimum quantity of naphthalene formaldehyde superplasticizer with respect to hardened cement paste strength is $1,0 \ldots 1,5 \%$ of the cement mass. The capillary porosity of cement paste distinctly decreases, but the size of capillary pores increases with adding naphthalene formaldehyde superplasticizer. Bigger than 1,0..1,5\% quantities of formaldehyde superplasticizer decrease water requirement for cement paste ineffectively and even decrease the strength of hardened paste.

In order to obtain a bigger water requirement reduction and to increase the strength of hardened cement paste it is possible to use admixture of lignosulfonate. By adding this admixture up to $0,3 \%$ (dry material) of cement mass water requirement for a normal consistency of cement paste increases proportionally with admixture quantity (Fig 3) and compressive strength of hardened cement paste increases proportionally and reaches considerably high values (Fig 4). 


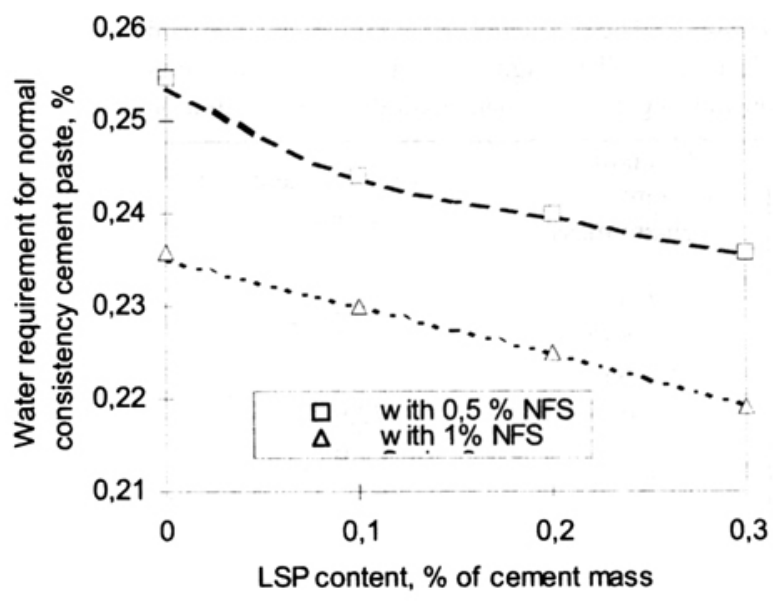

Fig 3. Relationship between water requirement for normal consistency cement paste and lignosulfonate (LSP) content

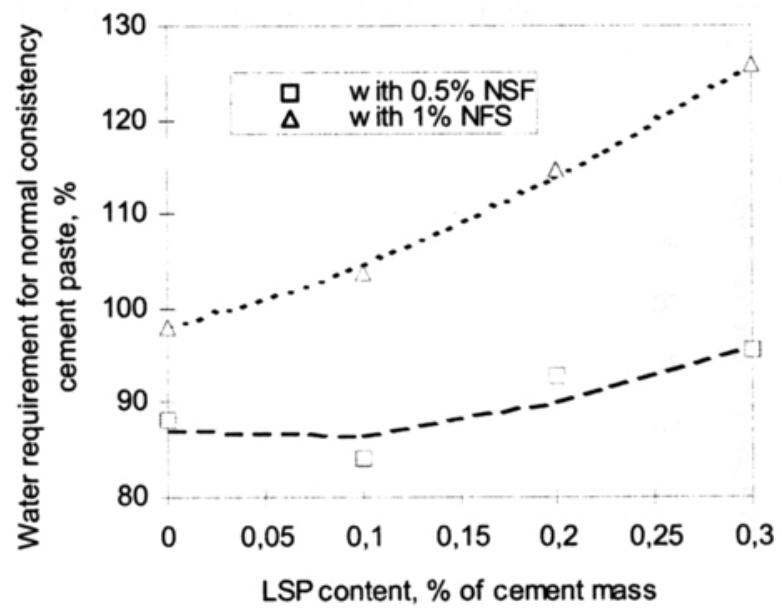

Fig 4. Relationship between compressive strength of hardened cement paste and lignosulfonate (LSP) content

A bigger quantity of naphthalene formaldehyde superplasticizer, lignosulfonate plasticizer increases the strength of hardened cement paste more. Lignosulfonate admixture decreases the degree of cement hydration more than naphthalene formaldehyde superplasticizer but just negligibly changes the quantity of $\mathrm{Ca}(\mathrm{OH})_{2}$ in hardened cement paste (Table 1). Due to the hydration deceleration, lignosulfonate admixture prolongs the cement paste setting time. While analysing the admixtures effect on the cement paste setting time, it was determined that the maximum quantity of lignosulfonate admixture in mixes with a $0,5 \%$ dosage of naphthalene formaldehyde superplasticizer is $0,3 \%$ and the maximum quantity of the same admixture with a $1,0 \%$ dosage of naphthalene formaldehyde superplasticizer is $0,2 \%$. Lignosulfonate admixtures, as naphthalene formaldehyde superplasticizer, decrease the capillary porosity of cement paste, decreasing at the same time the size of capillary pores.

Silica fume due to its very big specific surface area increases water requirement for normal consistency of cement paste proportionally to its quantity (Fig 5).

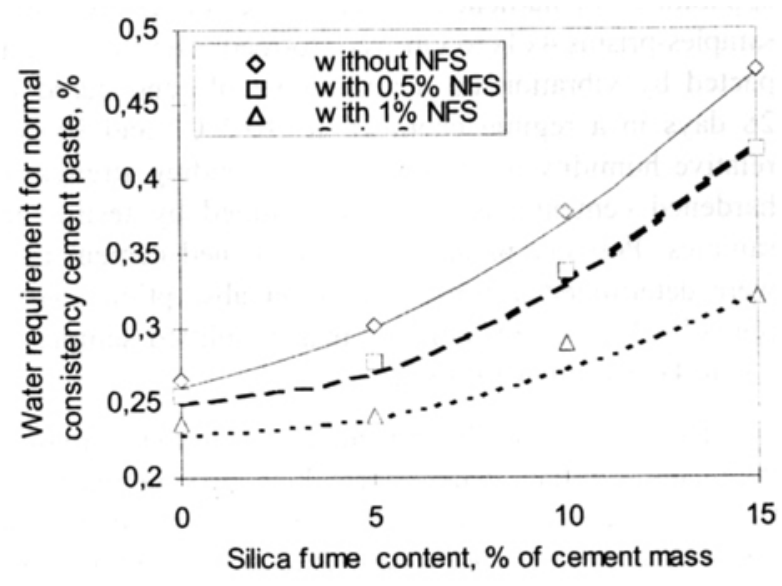

Fig 5. Relationship between water requirement for normal consistency cement paste and silica fume content

Fig 5 shows that silica fume increases the water requirement in mixes without plasticizing admixtures more than in mixes with them. The increase of water requirement and $\mathrm{V} / \mathrm{C}$ ratio has a negative effect on cement hydration terms as well as on hardened cement paste compressive and bending strength. With an increased $\mathrm{V} / \mathrm{C}$ ratio, silica fume had a considerable effect on cement hydration process and on the structure of hardened cement paste. Silica fume considerably increase the degree of cement hydration but in mixes with plasticizing admixtures the above-mentioned increase is being compensated by a plasticizing admixture which reduces the speed of hydration (Table 1). Silica fume rapidly reacts with $\mathrm{Ca}(\mathrm{OH})_{2}$ and an additional amount of hydration products - calcium hydrosilicate, forms [10]. In such a way the silica fume hydraulic activity is displayed. This has been proved by a considerably decreased amount of $\mathrm{Ca}(\mathrm{OH})_{2}$ in hardened cement paste (Table 1).

Formation of an additional amount of hydration products increases the hardened cement paste strength. Due to changes of $\mathrm{V} / \mathrm{C}$ ratio and silica fume hydraulic

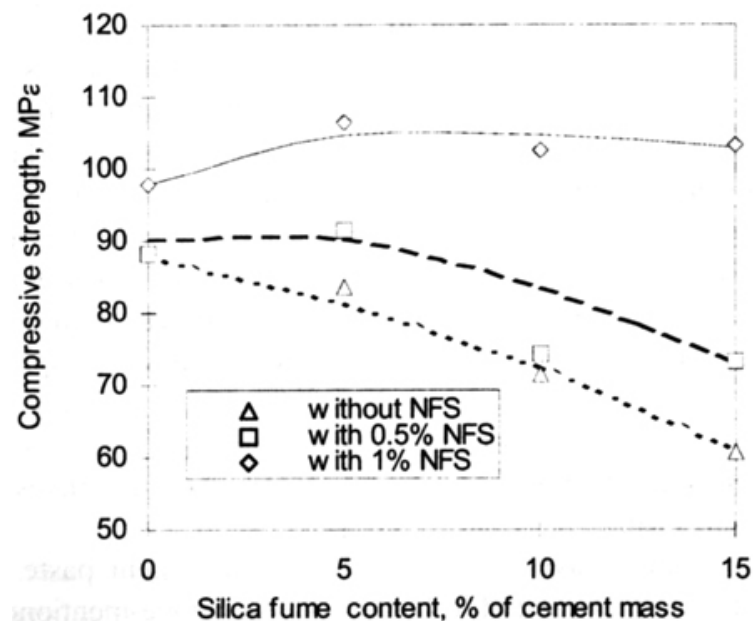

Fig 6. Relationship between hardened cement paste compressive strength and silica fume content 
activity, the reliability of hardened cement paste compressive strength dependence upon silica fume quantity has an extreme character (Fig 6).

In has been proved by experiments that the amount of capillary pores increases with the increase of silica fume quantity and that the size of capillary pores decreases with the increase of silica fume quantity up to a certain level.

The research results indicate that the optimum quantity of silica fume in cement pastes and concrete with a $0,5 \%$ dosage of naphthalene formaldehyde superplasticizer is $5 \%$ and with a $1 \%$ dosage of the above-mentioned superplasticizer is $7 \ldots 15 \%$ of cement mass (by the replacement of cement with a certain amount of silica fume).

\section{The research of silica fume mixing methods}

As silica fume is a very fine dispersive material, it is rather difficult to distribute it gradually in a cement mixture while mixing. Moreover, silica fume (for transport convenience) is granulated, before or during mixing it is necessary to dissolve its granules. Therefore silica fume mixing methods have been investigated.

During the research granulated silica fume from Norway, naphthalene formaldehyde superplasticizer REBA mix F2, portlandcement CEM I 52,5 produced by $\mathrm{AB}$ "Akmenès cementas" were used.

The following silica fume mixing methods have been used:

- grinding cement together with silica fume in a ball mill;

- mixing dry silica fume with cement;

- preparing silica fume suspension in water and later mixing it with cement;

- preparing silica fume suspension in a plasticizer solution and later mixing it with cement.

Fig 7 indicates that the most efficient silica fume mixing method is preparation of its suspension in a plasticizer solution and later mixing it with cement. Plasticizer in this case is being used as a deflocculant. Therefore this silica fume mixing method was used in all further investigations.

\section{High-strength concrete with complex admixtures}

According to the investigation results high-strength concretes have been produced by using naphthalene form-

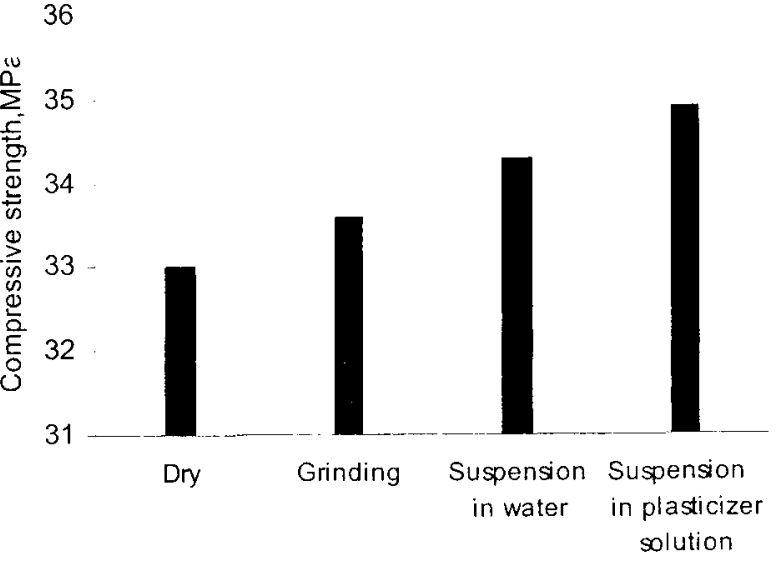

Fig 7. The influence of silica fume mixing method on hardened cement paste compressive strength

aldehyde or melamine formaldehyde superplasticizers, plasticizers on lignosulfonates base and silica fume.

Naphthalene formaldehyde superplasticizer "Muraplast NN", plasticizer on lignosulfonates base "Centrament N3", silica fume suspension and portlandcement CEM I 52,5, produced by AB "Akmenès cementas", crushed granite of $5 / 8$ and $11 / 16 \mathrm{~mm}$ fraction, produced by UAB "Nesta" have been used in this investigation. Lignosulfonates (plastificizer "Centrament N3") were dissolved in water and added to concrete mixture together with $80 \%$ of water and silica fume suspension. The rest amount of water together with superplasticizer was added at the end of mixing.

Two-stage mixing was used for preparing mixtures:

1) cement, aggregate, silica fume suspension, plasticizer and $80 \%$ of water were mixed for 2 minutes.

2) the rest of water together with superplasticizer was poured and mixed for additional 2 minutes.

$1,12 \%$ dosage (dry material) from the cement mass of naphthalene formaldehyde superplasticizer and $0,14 \%$ dosage (dry material) of the cement mass of lignosulfonates were added into mixture. $10 \%$ dosage (dry material) of the cement mass of silica fume was added as well. Volume concentration of coarse aggregate in all mixtures was 0,4 .

Concrete mixtures had a sufficient slump and rather stable - without separation and bleeding. Physical-mechanical characteristics of concrete after 7 days of curing in chamber regime are presented in Table 2.

Table 2. Physical and mechanical properties of high-strength concrete with complex admixtures

\begin{tabular}{|c|c|c|c|c|c|c|c|c|}
\hline $\mathrm{V} / \mathrm{C}$ & $\begin{array}{c}\text { Cement } \\
\text { content. } \\
\mathrm{kg} / \mathrm{m}^{3}\end{array}$ & $\begin{array}{c}\text { NFS } \\
\text { content, \% } \\
\text { of cement } \\
\text { mass }\end{array}$ & $\begin{array}{c}\text { LSP } \\
\text { content, \% } \\
\text { of cement } \\
\text { mass }\end{array}$ & $\begin{array}{c}\text { Silica fume } \\
\text { content, \% } \\
\text { of cement } \\
\text { mass }\end{array}$ & $\begin{array}{c}\text { Slump, } \\
\mathrm{cm}\end{array}$ & $\begin{array}{c}\text { Entrained } \\
\text { air, \% }\end{array}$ & $\begin{array}{c}\text { Concrete } \\
\text { density, } \\
\mathrm{kg} / \mathrm{m}^{3}\end{array}$ & $\begin{array}{c}\text { Concrete } \\
\text { compressive } \\
\mathrm{strength,} \mathrm{MPa}\end{array}$ \\
\hline 0,43 & 315 & 1,12 & 0,14 & 10 & 19 & 1,6 & 2441 & 73,6 \\
\hline 0,35 & 385 & 1,12 & 0,14 & 10 & 15 & 1,04 & 2440 & 79,4 \\
\hline 0,28 & 478 & 1,12 & 0,14 & 10 & 19 & 1,01 & 2443 & 83,9 \\
\hline
\end{tabular}


Using naphthalene formaldehyde superplasticizers together with lignosulfonates and silica fume, it is possible to produce a high-strength concrete, which strength is $73 \ldots 84 \mathrm{MPa}$ depending on $\mathrm{V} / \mathrm{C}$ ratio even after 7 days of curing.

\section{Conclusions}

1. The optimum content of naphthalene formaldehyde superplasticizer in high-strength concrete mixture is $1,0 \ldots 1,5 \%$ of dry material of cement mass.

2. The maximum content of lignosulfonates admixture in mixtures with a $0,5 \%$ dosage of naphthalene formaldehyde superplasticizer is $0,3 \%$ and with a $1,0 \%$ dosage of naphthalene formaldehyde superplasticizer is $0,2 \%$ of cement mass.

3. The naphthalene formaldehyde and lignosulfonates plasticizing admixtures decrease the degree of cement hydration as well as $\mathrm{Ca}(\mathrm{OH})_{2}$ quantity in hardened cement paste.

4. Optimum silica fume content in concrete with a $0,5 \%$ dosage of naphthalene formaldehyde superplasticizer is $5 \%$ and with a $1 \%$ dosage of the above-mentioned superplasticizer is $7 \ldots 15 \%$ of cement mass.

5. Silica fume increases the degree of cement hydration and decreases $\mathrm{Ca}(\mathrm{OH})_{2}$ quantity in a hardened concrete.

6. The best method of silica fume adding to concrete mixtures is the preparation of silica fume suspension in a plasticizer solution and later mixing it with dry components of concrete.

7. Complex usage of naphthalene formaldehyde and lignosulfonates plasticizers as well as silica fume and new mixtures preparation technologies determine the possibilities of production of high-strength concrete.

\section{References}

1. Ramachandar, V. S. Concrete admixtures handbook (Добавки в бетон. Справочное пособие). Moscow: Strojizdat, 1988, 575 p. (in Russian).
2. Babaev, Sh. T.; Komar, A. A. Energy saving technology of reinforced concrete structures from high-strength concrete with chemical admixtures (Энергосберегающая технология железобетонных конструкций из высокопрочного бетона с химическими добавками). Moscow: Strojizdat, 1987 , p. 64-78 (in Russian).

3. Morin, V.; Cohen Tenoudji, F.; Fyeylesoufi, A.; Richard, P. Superplasticizer effects on setting and structuration mechanisms of ultra-high-performance concrete. Cement and Concrete Research, 2001, No 31, p. 63-71.

4. Pierre-Claude Aitcin and Adam Neville. High-performance concrete. Concrete International, 1993, Vol 15, No 1, p 21 26

5. Kern, E. High-strength concrete technology. Concrete (Beton), 1993, No 3, p. 109-119 (in German).

6. Walraven, J. C. High-strength concrete production. B.F.T. (Betonwerk+Fertigteil-Technik), 1998, No 2, p. $68-72$ (in German).

7. Bottke, R.; Hinrichs, J. New B85 Concept for the site. B.F.T (Betonwerk+Fertigteil-Technik), 2001, No 5, p. 8284 (in German).

8. Okamura, H. Self-compacting high-performance concrete. Concrete International, 1997, No 7, p. 50-54.

9. Sasnauskas, K.; Skripkiūnas, G. Interaction of water and solid disperse phase in building mixtures. Chemical Technology (Chemijos technologija), 2001, No 4(21), p. 25-30 (in Lithuanian).

10. Yogendran, V.; Langan, B. W.; Haque, M. N.; Word, M. A. Silica fume in high-strength concrete. ACI Materials Journal, 1987, No 2, p. 125-129.

11. Alshamsi, A. M.; Sabouni, A. R.; Bushlaibi, A. H. Influence of set-retarding superplasticizers and microsilica on setting times of pastes of various temperatures. Cement and Concrete Research, 1993, No 3, p. 593-598.

12. Xu, G.; Watt, D.; Hudec, P. Effectiveness of mineral admixtures in reducing ASR expansion. Cement and Concrete Research, 1995, Vol 25, No 6, p. 1225-1236.

13. Pigeon, M.; Aitcin, P. C.; Laplante, P. Comparative study of condensed silica-fume field concrete. ACI Materials Journal, 1987, No 3, p. 194-199.

14. Toutanji, A.; Bayasi, Z. Effect of curing procedures on properties of silica-fume concrete. Cement and Concrete Research, 1999, No 29, p. 497-501. 